\title{
Carotid stenosis: current concepts and future prospects
}

\author{
Estenose carotídea: conceitos atuais e perspectivas futuras
}

Edwaldo Edner Joviliano'

Cerebral vascular accidents (strokes) are one of the most common causes of death and the leading cause of persistent and acquired disability in adults worldwide. In view of changing demographics, it is to be expected that there will be even greater increases in stroke incidence rates. Furthermore, strokes are likely to affect ever younger patients. The World Health Organization (WHO) has described strokes as an early $21^{\text {st }}$ century epidemic. As such, strategies for prevention of strokes are currently of prime importance, particularly in view of recent studies suggesting that $85 \%$ of all strokes could be prevented. ${ }^{1}$

Within this scenario, atherosclerotic disease of the carotid is the most common cause of carotid obstruction and exhibits significant correlations and concomitance with atherosclerotic disease in other territories, such as in the coronary territory and the peripheral vascular territory, particularly in the lower limbs. From $10 \%$ to $15 \%$ of all ischemic strokes have their origins in stenosis at the level of the internal carotid artery. In patients with carotid disease, the purpose of carotid revascularization is prevention of (recurrent) stroke. For more than 50 years, carotid endarterectomy (CEA) has been considered the standard treatment for severe symptomatic stenosis. Over the last 15 years, carotid artery stenting (CAS) has emerged as a minimally invasive alternative to surgery. ${ }^{2}$ Notwithstanding, its role remains highly controversial. The debate has been fed by contributions from the many different medical specialties involved and by the disappointing results of CAS demonstrated in randomized comparisons with CEA. While some people have interpreted these conclusions as clinical evidence, others have suggested that the majority of trials have not compared the two revascularization techniques appropriately. ${ }^{3}$ Despite countless studies of the subject, certain questions remain controversial, both with regard to clinical management, in terms of whether to prescribe interventions for asymptomatic patients, and with regard to choosing between surgical or minimally invasive management of patients with symptomatic carotid stenosis.
The prevalence of asymptomatic $>50 \%$ carotid stenosis increases with age and in patients with heart disease, diabetes mellitus, and in smokers. However, patients with carotid stenosis are at four times greater risk of myocardial infarction than of stroke. ${ }^{4}$ While endarterectomy for symptomatic carotid stenosis is a treatment that has proven to be beneficial for secondary prevention of stroke, its value in asymptomatic stenosis remains controversial. Randomized clinical trials conducted in the 1990s suggested that benefits of surgery in asymptomatic patients with carotid stenosis were from $\geq 60 \%$ to $\geq 70 \%$ (a relative risk reduction of $50 \%$ ), providing that perioperative complication rates were lower than $3 \%$ and patients had $\geq 5$ years' life expectancy.,5 Considering that the reduction in absolute risk was just $1 \%$ per year, however, the treatment effect was very modest. The 5 -year long-term risk of an ipsilateral stroke and any type of stroke or perioperative death was $5.1 \%$ for surgery patients and $11 \%$ for patients treated clinically, and the difference was highly significant. Despite differences in methods, these results were reproduced in another large European study of asymptomatic carotid disease more than a decade later in the Asymptomatic Carotid Surgery Trial (ACST). ${ }^{6}$ This multicenter randomized study allocated patients either to immediate CEA or to delayed CEA and drug-based treatment. The ACST data forms the largest body of evidence in support of prophylactic endarterectomy for high-grade asymptomatic carotid stenosis $(>80 \%)$ and the trial recently reported the benefits of CEA compared with drug treatment at 10-year follow-up.

Recent studies suggest that the risk of stroke is less than $1 \%$ per year for patients with asymptomatic carotid stenosis who are treated using the "best medical therapy" (BMT), which was primarily attributed to regular use of platelet antiaggregant drugs, statins and antihypertensives and to lifestyle changes. These new observations call into question the value of surgery for asymptomatic patients. ${ }^{8}$ The question has now become: How strict will clinical compliance with this 
treatment (BMT) be in the real world and for how long can these better results be maintained?

Six large randomized studies with a total of 6,780 patients have compared CAS against CEA. While the SAPPHIRE study (Stenting and Angioplasty with Protection in Patients at High Risk for Endarterectomy) included both symptomatic and asymptomatic patients with high surgical risk, ${ }^{9}$ the CAVATAS (Carotid and Vertebral Artery Transluminal Angioplasty Study), ${ }^{10}$ SPACE (Stent-Protected Percutaneous Angioplasty of the Carotid Artery vs. Endarterectomy), ${ }^{11}$ 5EVA-3S (Endarterectomy vs. Angioplasty in Patients with Symptomatic Severe Carotid Stenosis) ${ }^{12}$ and ICSS (International Carotid Stenting Study) studies all recruited symptomatic patients with standard surgical risk levels. ${ }^{13}$ Finally, the CREST (Carotid Revascularization Endarterectomy vs. Stenting Trial) study enrolled both symptomatic and asymptomatic patients, with standard surgical risk. ${ }^{14}$ For different reasons, these randomized studies were each compromised by limitations, the most important of which was the limited expertise of the endovascular professionals who conducted the CAS procedures.

Curiously, in the CREST study an age effect on the results was also observed, demonstrating that age is an important factor in choosing the best treatment for a given patient. Patients who underwent CAS at age 75 or older had an incidence of myocardial infarction, stroke or death of $12.7 \%$, compared with $6.3 \%$ for those $65-74$ years old and $3.9 \%$ for younger patients $(\mathrm{p}<0.0001) .{ }^{15}$ However, the age effect was not observed in patients treated with CEA. The patients who underwent CEA had similar risk levels in the three age categories $(6.1 \%$ at $<64$ years, $6.3 \%$ at $65-74$ years, and $7.4 \%$ at $>75$ years, $p<0.5)$. When CEA and CAS were compared, there was no difference in the incidence of the primary outcome between patients in the two younger age groups. ${ }^{2}$ However, in patients $>75$ years, incidence was significantly higher for CAS (12.7\% CAS vs. 7.4\% CEA, $p=0.05)$, with a statistically significant interaction with age $(p=0.02)$. The increase in the incidence of the primary outcome in the CAS group was primarily due to the increasing rate of strokes as age increased. This tendency was not observed in patients treated with CEA.

As our readers know, there is much ongoing research that is attempting to stratify and qualify imaging exams and serum markers of plaques to help in assessing their vulnerability and their instability. The first data from these studies revealed that patients treated with CEA for symptomatic stenosis were more likely to have soft plaques than patients treated with CEA for asymptomatic disease. Additionally, a biobank of carotid plaques is being studied to identify biomarkers that could aid in identification of vulnerable and unstable plaques. ${ }^{16}$

In response to the growing uncertainty surrounding clinical management of asymptomatic patients with carotid artery disease, the National Institutes of Health (NIH) is financing the CREST-2 trial. This multicenter randomized study has two arms related to intervention, CEA vs. BMT and CAS vs. BMT. Patients can opt to enroll in either the CEA or CAS arms. Randomization therefore decides between intervention or BMT, rather than between types of intervention (CEA or CAS) Patients allocated to CEA or CAS will also receive the same BMT as those randomized to medical treatment. The study will probably take around a decade to complete randomization and produce results for at least 4 years' follow-up. ${ }^{17}$ Another pertinent question to be answered in forthcoming studies is: Faced with an acute stroke associated with ipsilateral carotid stenosis, which is the best treatment option, BMT, CEA or CAS? Interaction between professionals specialized in treating neurovascular diseases and vascular surgeons becomes ever more important in the ongoing search for the best approach to carotid disease.

\section{REFERENCES}

1. O'Donnell MJ, Xavier D, Liu L, et al. Risk factors for ischaemic and intracerebral haemorrhagic stroke in 22 countries (the INTERSTROKE study): a case-control study. Lancet. 2010;376(9735):112-23. http:// dx.doi.org/10.1016/S0140-6736(10)60834-3. PMid:20561675.

2. Roffi M, Mukherjee D, Clair DG. Carotid artery stenting vs. endarterectomy. Eur Heart J. 2009;30(22):2693-704. http://dx.doi. org/10.1093/eurheartj/ehp471. PMid:19861324.

3. Roffi $M$, Sievert $H$, Gray WA, et al. Carotid artery stenting versus surgery: adequate comparisons? Lancet Neurol. 2010;9(4):339-41. http://dx.doi.org/10.1016/S1474-4422(10)70027-2. PMid:20189459.

4. Goessens BM, Visseren FL, Kappelle LJ, Algra A, van der Graaf Y. Asymptomatic carotid artery stenosis and the risk of new vascular events in patients with manifest arterial disease: the SMART study. Stroke. 2007;38(5):1470-5. http://dx.doi.org/10.1161/ STROKEAHA.106.477091. PMid:17363718.

5. Walker MD. Endarterectomy for asymptomatic carotid artery stenosis. Executive Committee for the Asymptomatic carotid Atherosclerosis Study. JAMA. 1995;273(18):1421-8. http://dx.doi. org/10.1001/jama.1995.03520420037035. PMid:7723155.

6. MRC Asymptomatic Carotid Surgery Trial (ACST) Collaborative Group. Prevention of disabling and fatal strokes by successful carotid endarterectomy in patients without recent neurological symptoms: randomised controlled trial. Lancet. 2004;363(9420):1491-502. http://dx.doi.org/10.1016/S0140-6736(04)16146-1. PMid:15135594.

7. Halliday A, Harrison M, Hayter E, et al. 10-year stroke prevention after successful carotid endarterectomy for asymptomatic stenosis (ACST1): a multicentre randomised trial. Lancet. 2010;376(9746):1074-84. http://dx.doi.org/10.1016/S0140-6736(10)61197-X. PMid:20870099. 
8. Abbott AL. Medical (nonsurgical) intervention alone is now best for prevention of stroke associated with asymptomatic severe carotid stenosis: results of a systematic review and analysis. Stroke. 2009;40(10):e573-83. http://dx.doi.org/10.1161/ STROKEAHA.109.556068. PMid:19696421.

9. Yadav JS, Wholey MH, Kuntz RE, et al. Protected carotid-artery stenting versus endarterectomy in high-risk patients. N Engl J Med. 2004;351(15):1493-501. http://dx.doi.org/10.1056/NEJMoa040127. PMid:15470212.

10. CAVATAS Investigators. Endovascular versus surgical treatment in patients with carotid stenosis in the Carotid and Vertebral Artery Transluminal Angioplasty Study (CAVATAS): a randomised trial. Lancet. 2001;357(9270):1729-37. http://dx.doi.org/10.1016/ S0140-6736(00)04893-5. PMid:11403808.

11. SPACE Collaborative Group. 30 day results from the SPACE trial of stent-protected angioplasty versus carotid endarterectomy in symptomatic patients: a randomised non-inferiority trial. Lancet. 2006;368(9543):1239-47. http://dx.doi.org/10.1016/ S0140-6736(06)69122-8. PMid:17027729.

12. Mas JL, Chatellier G, Beyssen B, et al. Endarterectomy versus stenting in patients with symptomatic severe carotid stenosis. N Engl J Med. 2006;355(16):1660-71. http://dx.doi.org/10.1056/ NEJMoa061752. PMid:17050890.

13. International Carotid Stenting Study investigators. Carotid artery stenting compared with endarterectomy in patients with symptomatic carotid stenosis (International Carotid Stenting Study): an interim analysis of a randomised controlled trial. Lancet. 2010;375(9719):985-97. http://dx.doi.org/10.1016/S01406736(10)60239-5. PMid:20189239.
14. Brott TG, Hobson RW 2nd, Howard G, et al. Stenting versus endarterectomy for treatment of carotid-artery stenosis. N Engl J Med. 2010;363(1):11-23. http://dx.doi.org/10.1056/NEJMoa0912321. PMid:20505173.

15. Khatri R, Chaudhry SA, Vazquez G, et al. Age differential between outcomes of carotid angioplasty and stent placement and carotid endarterectomy in general practice. J Vasc Surg. 2012;55(1):72-8 http://dx.doi.org/10.1016/j.jvs.2011.08.007. PMid:22070935.

16. Bazan HA, Smith TA, Donovan MJ, Sternbergh WC 3rd. Future management of carotid stenosis: role of urgent carotid interventions in the acutely symptomatic carotid patient and best medical therapy for asymptomatic carotid disease. Ochsner J. 2014;14(4):608-15. PMid:25598726.

17. National Library of Medicine - NLM. [site da Internet].Carotid Revascularization and Medical Management for Asymptomatic Carotid Stenosis Trial (CREST-2). Bethesda: NLM; 2015. [citado 2015 jun 12]. https://clinicaltrials.gov/ct2/show/NCT02089217

Correspondence
Edwaldo Edner Joviliano
Universidade de São Paulo - USP
Av. dos Bandeirantes, 3900, Campus Universitário, HC, $9^{\circ}$ andar -
Monte Alegre
CEP 14040-900 - Ribeirão Preto (SP), Brazil
E-mail: eejov@fmrp.usp.br
Author information
Associate professor of the Division of Vascular and Endovascular
Surgery, Department of Surgery and Anatomy, Ribeirão Preto Medical
School, Universidade de São Paulo (USP).

